\title{
Synthesis, Characterization and Metal Ion Adsorption Studies on Novel Aromatic Poly(Azomethine Amide)s Containing Thiourea Groups
}

\author{
Lingam Ravikumar ${ }^{1 *}$, Selvaraj Kalaivani ${ }^{2}$, Thangaraj Vidhyadevi², \\ Arukkani Murugasen ${ }^{2}$, Selvaraj Dinesh Kirupha², Subramanian Sivanesan ${ }^{2}$ \\ ${ }^{1}$ Department of Chemistry, C.B.M. College, Bharathiar University, Coimbatore, India \\ ${ }^{2}$ Department of Applied Science and Technology, Anna University, Chennai, India \\ Email: ravikumarcbm@rediffmail.com
}

Received December 28, 2013; revised January 28, 2014; accepted February 5, 2014

Copyright (c) 2014 Lingam Ravikumar et al. This is an open access article distributed under the Creative Commons Attribution License, which permits unrestricted use, distribution, and reproduction in any medium, provided the original work is properly cited. In accordance of the Creative Commons Attribution License all Copyrights (C) 2014 are reserved for SCIRP and the owner of the intellectual property Lingam Ravikumar et al. All Copyright (C) 2014 are guarded by law and by SCIRP as a guardian.

\section{ABSTRACT}

A series of novel ladder-type poly(azomethine amide)s (PAMs) were prepared from new azomethine containing carboxylic acid monomer (TCA) with simple aromatic diamines and aromatic diamines with thiourea groups (TDAs) by means of phosphorylation polycondensation reaction. Molecular weights of the polyamides were evaluated viscometrically, and the inherent viscosities were in the range of 0.31 - 0.58 g/dl. These ladder-type polymers were not freely soluble in common organic solvents. Structure of monomers and polymers were confirmed using FT-IR, ${ }^{1} \mathrm{H}$-NMR and ${ }^{13} \mathrm{C}-\mathrm{NMR}$ spectroscopic analysis. Removal of $\mathrm{Cu}^{2+}$ and $\mathrm{Cd}^{2+}$ from aqueous solutions by adsorption onto the polyamides was investigated. The effect of pH, initial metal ion concentrations and contact time were studied in batch experiments. The polyamides were found to be highly effective adsorbents for the removal of $\mathrm{Cu}^{2+}$ and $\mathrm{Cd}^{2+}$ metal ions from aqueous solutions. In a mixture of metal ions, the selectivity order was found to be $\mathrm{Pb}(\mathrm{II})>\mathrm{Cu}(\mathrm{II})>\mathrm{Cr}(\mathrm{IV})>\mathrm{Cd}(\mathrm{II})$.

\section{KEYWORDS}

\section{Polyamide; Azomethine; Phenyl Thiourea; Ladder Type; Heavy Metal Ion Removal}

\section{Introduction}

Aromatic polyamides have received special interest as polymeric materials for advanced technologies due to their excellent balance of mechanical, thermal and chemical properties. They have been widely used in the fields of electrical materials, adhesives, composites and membranes [1]. Structural modifications of the chemical structure in polyamides have been made to improve desirable properties such as solubility, physical and chemical stability. Introduction of carbon-nitrogen double bonded azomethine units into a polymer backbone not only enhances the thermal stability, semi conductivity but also improves protonation and complexation ability [2-4]. Poly(azomethine amide)s reported so far mainly

\footnotetext{
"Corresponding author.
}

focussed to improve the polymer solubility, thermal stability and liquid crystalline properties [4-8]. Inclusion of phenylthiourea groups into polymer backbone has gained great importance for its excellent properties such as corrosion resistance, thermal stability, semi conductivity and binding to metal ions [9-11]. Polythioamides are well known in which the amide carbonyl oxygen is replaced with sulfur [12]. However, polyesters or polyamides bearing both azomethine and thiourea groups are different from polythioamides and is a relatively less explored area [13-15]. The aim of this investigation is to synthesize new polyamides in which azomethine groups are present in a ladder type structure and thiourea groups in the main chain. Such a ladder type structure enhances the chemical stability of the polyamides that makes them suitable for the removal of heavy metal ions from indus- 
trial effluents.

Heavy metals may come from various industrial sources such as electroplating, storage batteries, ceramic and glass industries. $\mathrm{Cu}^{2+}$ and $\mathrm{Cd}^{2+}$ are common contaminants of industrial waters. They are highly toxic to human beings, pose serious environmental problems and are definitely undesirable elements in industrial wastes. Considerable attention has been paid to the development of processes for the removal of $\mathrm{Cd}^{2+}$ and $\mathrm{Cu}^{2+}$ ions from industrial waste waters $[16,17]$. Methods such as membrane filtration, ion exchange and electrolysis are not widely used because of their high cost and low feasibility [18]. On the other hand, conventional adsorbents such as activated carbon is not economically viable and technically efficient [19]. Thiourea and methyl thiourea based polymers were reported for the removal of $\mathrm{Cu}^{2+}, \mathrm{Cd}^{2+}$ and $\mathrm{Fe}^{3+}[20,21]$. Recently, Schiff based polymers of chitosen and thiourea based polymers were developed for the removal of $\mathrm{Cu}^{2+}$ and other metal ions [22-24]. Our group is currently concentrating on the synthesis of novel polymers bearing hetero atoms in the polymer back bone for the efficient removal of heavy metal ions [25-28]. In this study new ladder type poly(azomethine amide)s having phenyl thiourea groups were synthesized, characterized and their potential application as adsorbents for the removal of $\mathrm{Cu}^{2+}$ and $\mathrm{Cd}^{2+}$ from aqueous solutions were explored.

\section{Experimental}

\subsection{Materials}

Diaminodiphenyl ether, oxydianilene, diaminodiphenyl sulfone (all from Aldrich) were recrystallized before use. Terephthalaldehyde (Fluka) was used as received. DMF was stored over calcium hydride and distilled under reduced pressure.NMP was kept over $\mathrm{P}_{2} \mathrm{O}_{5}$, and distilled under reduced pressure. Pyridine was refluxed with $\mathrm{KOH}$ for $30 \mathrm{~min}$. and distilled. Triphenyl phosphite (Aldrich) was used as received. All other chemicals and reagents were purified according to standard procedures.

\subsection{Synthesis of Tetracarboxylic Acid Monomer (TCA)}

Terephthalaldehyde $2.0 \mathrm{~g}$ (0.015 mol.), 2-aminoterephthalic acid $5.5 \mathrm{~g}\left(0.03 \mathrm{~mol}\right.$.), two drops Conc $\cdot \mathrm{H}_{2} \mathrm{SO}_{4}$ were charged into a $250 \mathrm{ml}$ three necked round bottomed flask containing $25 \mathrm{ml}$. of DMF with a $\mathrm{N}_{2}$ inlet, condenser and a Dean-Stark apparatus. The contents were heated to $110^{\circ} \mathrm{C}$ for $1 \mathrm{~h}$. and the azeotrope formed was removed. After removing the Dean-Stark apparatus, 5 $10 \mathrm{ml}$. of DMF was distilled under reduced pressure. The contents were further heated for $3 \mathrm{~h}$. with magnetic stirring. The yellow solid formed was washed with hot water, ethanol and recrystallized from DMF/water mixture.
Yield: 82\%, Colour: yellow. IR: $3100 \mathrm{~cm}^{-1}$ (-OH of $\mathrm{COOH}), 1687 \mathrm{~cm}^{-1}$ (C=O St.) $1623 \mathrm{~cm}^{-1}$ (-N=CH- St.). $500 \mathrm{MHz} 1 \mathrm{H}-\mathrm{NMR}$ in DMSO-d $6^{-} \delta=10.1 \mathrm{ppm}(4 \mathrm{H}$, $-\mathrm{COOH}), \delta=8.7 \mathrm{ppm}(2 \mathrm{H},-\mathrm{N}=\mathrm{CH}), \delta=8.1-6.5 \mathrm{ppm}$ (10H, Ar.H).

\subsection{Synthesis of Phenylthiourea Diamines (TDA)}

All the phenylthiourea diamines were prepared as reported earlier [10]. The procedure for 4,4'-bis(thiourea) diphenyl ether is described here. The $250 \mathrm{ml}$ round bottomed flask was charged with $0.01 \mathrm{~mol}$. of recrystallized 4,4'-diaminodiphenyl ether, $45 \mathrm{ml}$. of deareated water, $10 \mathrm{ml}$. Conc. $\mathrm{HCl}$ and a pinch of activated charcoal and warmed to $50^{\circ} \mathrm{C}$ with constant stirring using a magnetic stirrer for about 20 min. The resulting mixture was filtered and transferred into another $250 \mathrm{ml}$. round-bottomed flask fitted with a condenser, a thermometer, and a stirrer. 0.04 mol. of ammonium thiocyanate was added and heated to $90^{\circ} \mathrm{C}$ for about $48 \mathrm{~h}$. The yellow granular product thus obtained was allowed to cool washed with hot water. It was then recrystallized using DMSO/water, filtered and dried under vacuum at $60^{\circ} \mathrm{C}$. Yield: $68 \%$. Colour: yellow. FT-IR: $3268 \mathrm{~cm}^{-1}$ (-NH $\left.\mathrm{NH}_{2} \mathrm{St}\right), 3175 \mathrm{~cm}^{-1}$ (-NH St), $1547 \mathrm{~cm}^{-1}$ (-NH deformation), $1067 \mathrm{~cm}^{-1}$ (C=S St.). ${ }^{1} \mathrm{H}-\mathrm{NMRin}$ DMSO-d $\mathrm{d}_{6^{-}} \delta=9.48 \mathrm{ppm}(2 \mathrm{H},-\mathrm{NH}), \delta=$ $7.15 \mathrm{ppm}(4 \mathrm{H}, \mathrm{Ar}), \delta=7.04 \mathrm{ppm}(4 \mathrm{H}, \mathrm{Ar}$ ), $\delta=3.81(4 \mathrm{H}$, $\left.-\mathrm{NH}_{2}\right)$.

\subsection{Preparation of Polymers}

Direct polycondensation of the azomethine containing tetracarboxylic acid monomer with diamines and diamines having thiourea groups were carried out in NMP using $\mathrm{P}(\mathrm{OPh})_{3}$ and pyridine as condensing agents and TEA. $\mathrm{HCl}$ as catalyst at $140^{\circ} \mathrm{C}$. Preparation of PAM I is explained. Into a flat bottomed flask was charged with $0.5 \mathrm{~g}\left(1.086 \times 10^{-3} \mathrm{~mol}\right.$. $)$ TCA, $0.4353 \mathrm{~g}\left(2.17 \times 10^{-3}\right.$ mol.) of TDA, $1.2 \mathrm{ml}$. $\left(4.377 \times 10^{-3} \mathrm{~mol}\right.$.) $\mathrm{P}(\mathrm{OPh})_{3}$, $0.5979 \mathrm{~g}\left(4.34 \times 10^{-3}\right.$ mol. $)$ TEA.HCl, $1.5 \mathrm{ml}$ pyridine and $10 \mathrm{ml}$ of NMP. The contents were refluxed with a magnetic stirrer at $140^{\circ} \mathrm{C}$ for $6 \mathrm{~h}$. It was then allowed to cool to room temperature and the viscose solution formed was poured into $200 \mathrm{ml}$ of absolute ethanol with stirring. The precipitate formed was filtered, washed with water, dil. $\mathrm{Na}_{2} \mathrm{CO}_{3}$, dil.HCl, water and ethanol and dried in vacuum.

\subsection{Metal ion Adsorption Experiments}

Batch adsorption experiments were conducted in $50 \mathrm{ml}$. flasks. Poly(azomethine amide)s ( $0.02 \mathrm{~g}$ ) was added into $20 \mathrm{ml}$ solution with a predetermined $\mathrm{pH}$ value and a known metal ion concentrations $\left(\mathrm{CuSO}_{4} \cdot 5 \mathrm{H}_{2} \mathrm{O}\right.$, $\left.\mathrm{CdSO}_{4} \cdot 8 \mathrm{H}_{2} \mathrm{O}, \mathrm{K}_{2} \mathrm{Cr}_{2} \mathrm{O}_{7}, \mathrm{~Pb}(\mathrm{NO})_{3}\right)$. The mixture was shaken for $1 \mathrm{~h}$ at room temperature. Then the supernatant 
solutions were removed for the $\mathrm{Cu}^{2+}$ and $\mathrm{Cd}^{2+}$ concentrations using atomic absorption spectrometer. The experiments were performed at different $\mathrm{pH}$, initial metal ion concentration and contact time. Selectivity studies were performed using mixture of metal ions of predetermined concentrations. Recyclability of the polymers with mixture of metal ion solutions was tested using $0.2 \mathrm{M} \mathrm{HCl}$ as an eluting solvent. The amount of metal ions adsorbed was calculated from the following equation.

$$
\mathrm{q}_{\mathrm{e}}=\left(\mathrm{C}_{0}-\mathrm{C}_{\mathrm{e}}\right) \mathrm{V} / \mathrm{W}
$$

where $\mathrm{C}_{0}$ and $\mathrm{C}_{\mathrm{e}}$ are the initial and equilibrium metal ion concentrations $(\mathrm{mg} / \mathrm{L})$ respectively, $\mathrm{V}$ is the volume of the solution and $\mathrm{W}$ is the weight of polymer used.

\section{Characterization}

Inherent viscosities were determined by using an Ubbelohde viscometer in a concentration of $0.5 \mathrm{~g} / \mathrm{dL}$ in DMSO at $25^{\circ} \mathrm{C}$. IR measurements were carried out on a Spectrumone, Perkin Elmer ATR, without $\mathrm{KBr}$ for all the samples except for the samples of metal ion adsorbed polymers, which were recorded using $\mathrm{KBr}$ pellets. ${ }^{1} \mathrm{H}$ and ${ }^{13} \mathrm{C}$ - NMR spectra were obtained in DMSO- $\mathrm{d}_{6}$ using a Bruker AVIII spectrometer. TGA were performed on a Perkin-Elmer analyzer in $\mathrm{N}_{2}$ at a heating rate of $10^{\circ} \mathrm{C}$ $\mathrm{min}^{-1} \cdot \mathrm{Cu}^{2+}$ and $\mathrm{Cd}^{2+}$ concentrations were determined using AA6300 Atomic absorption spectrometer (Shimadzu).

\section{Results and Discussion}

\subsection{Monomer Synthesis}

The tetra carboxylic acid monomer (TCA) was synthesized by simple condensation reaction between 4 -aminoterephthalic acid and terephthaldehyde (2:1 mol. ratio). The $-\mathrm{NH}_{2}$ stretching frequency of 4-aminoterephthalic acid (Figure 1) appeared at 3505 and $3388 \mathrm{~cm}^{-1}$ is not seen in the IR spectrum of TCA (Figure 2). The $-\mathrm{N}=\mathrm{CH}$ - stretching frequency of TCA appeared at 1623 $\mathrm{cm}^{-1}$, which confirms the completion of the reaction between $-\mathrm{NH}_{2}$ and $-\mathrm{CHO}$ groups of the precursors. The $\mathrm{C}=\mathrm{O}$ stretching frequency of the acid group is confirmed through the absorption band at $1687 \mathrm{~cm}^{-1}$. The hydrogen bonded $-\mathrm{OH}$ stretching frequency of the acid group appeared as a broad band around $3100 \mathrm{~cm}^{-1}$. The ${ }^{1} \mathrm{H}-\mathrm{NMR}$ (500 MHz, DMSO- $\mathrm{d}_{6}$ ) spectrum of TCA is shown in Figure 3. $\delta=8.78 \mathrm{ppm}$ is due to the $-\mathrm{N}=\mathrm{CH}$ - protons and no signals were obtained for the $-\mathrm{CHO}$ and $-\mathrm{NH}_{2}$ protons which suggests the formation of the monomer TCA. The other observations of the signals are: $\delta=10.14$ $\operatorname{ppm}(4 \mathrm{H},-\mathrm{COOH}), \delta=8.18-6.5$ are due to the 10 aromatic protons. ${ }^{13} \mathrm{C}-\mathrm{NMR}\left(500 \mathrm{MHz}, \mathrm{DMSO}-\mathrm{d}_{6}, \delta\right.$, ppm) of monomer TCA is shown and explained in Figure 4. 162.2 $\left(\mathrm{C}_{3}\right), 155.5\left(\mathrm{C}_{4}\right), 153.6\left(\mathrm{C}_{5}\right), 140.9\left(\mathrm{C}_{6}\right), 131.0\left(\mathrm{C}_{7}\right)$,

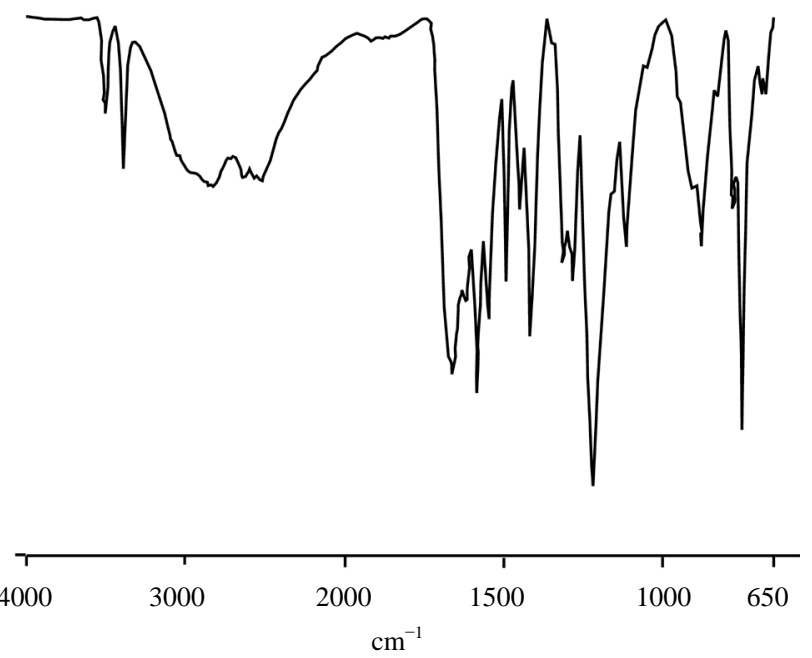

Figure 1. IR-Spectrum of 4-aminoterephthalic acid.

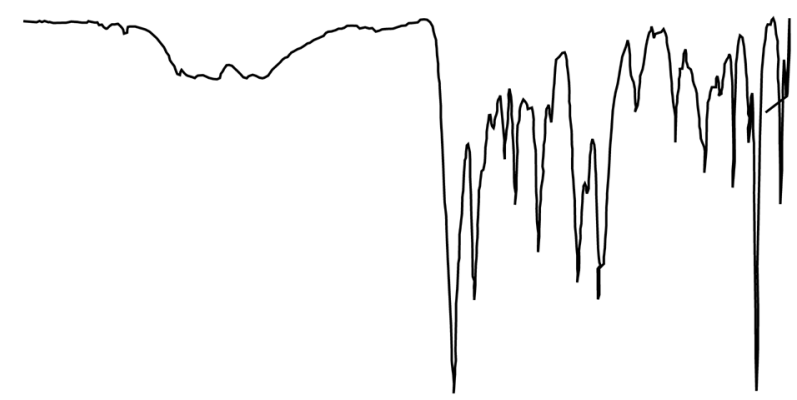

\begin{tabular}{lccccc}
\hline 4000 & 3000 & $\begin{array}{r}2000 \\
\mathrm{~cm}^{-1}\end{array}$ & 1500 & 1000 & 650
\end{tabular}

Figure 2. IR-Spectrum of TCA.

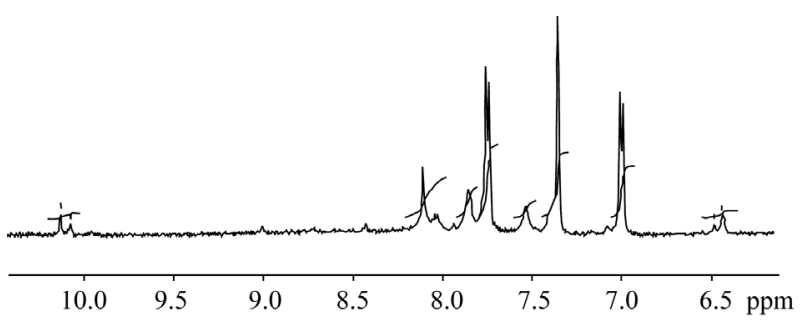

Figure $3 .{ }^{1} \mathrm{H}$-NMR-Spectrum of TCA.

130.3 $\left(\mathrm{C}_{8}\right)$, 128.9( $\left.\mathrm{C}_{9}\right)$, 121.6( $\left.\mathrm{C}_{10}\right), 117.3\left(\mathrm{C}_{11}\right)$ and 113.2( $\left.\mathrm{C}_{12}\right)$. The acid groups carbon $\mathrm{C}_{1}$ and $\mathrm{C}_{2}$ appear at 167.9 and 167.4 respectively.

Synthesis of phenylthiourea containing diamines (TDAs) was accomplished according to our earlier report [10]. The structure of the phenylthiourea diamines were confirmed with IR and ${ }^{1} \mathrm{H}-\mathrm{NMR}$ analysis. The FT-IR spectrum of TDA-IV is shown in Figure 5. The $-\mathrm{NH}_{2}$ signals of 4,4'-diaminodiphenyl ether appears as doublet at $3413 \mathrm{~cm}^{-1}$. However, with the introduction of thioamide group in the monomer TDA-IV, $-\mathrm{NH}_{2}$ signals 


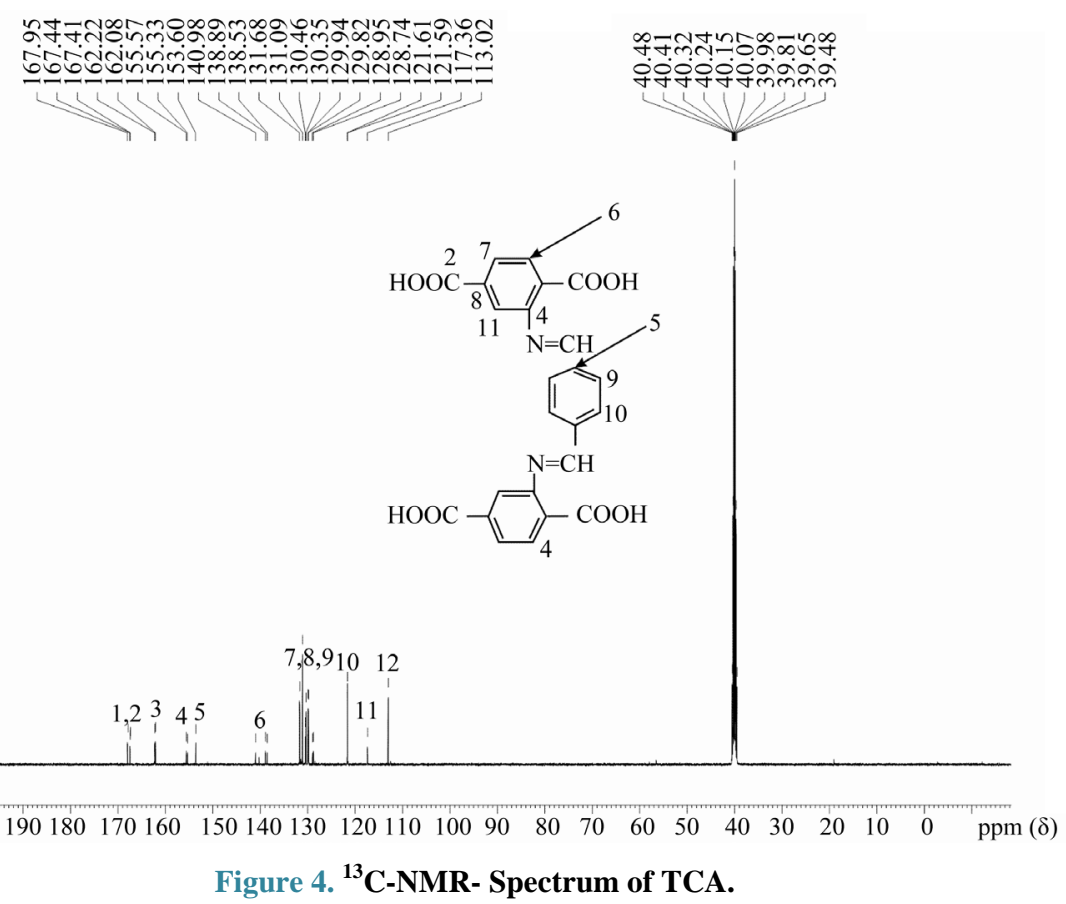

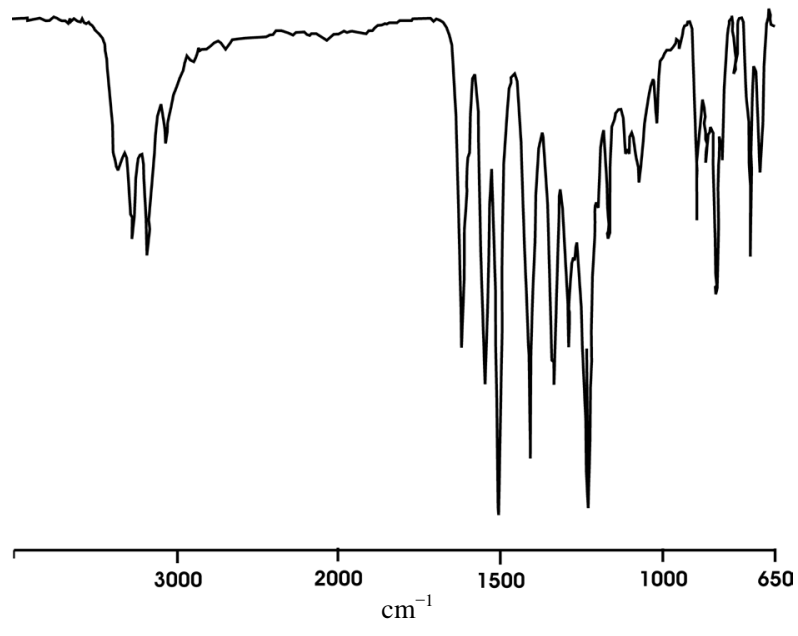

Figure 5. FT-IR-Spectrum of TDA-IV.

shifted as doublet to $3268 \mathrm{~cm}^{-1}$ and the $-\mathrm{NH}$ St. frequency appeared at $3175 \mathrm{~cm}^{-1}$. The $\mathrm{C}=\mathrm{S}$ St. frequency is shown at $1067 \mathrm{~cm}^{-1}$. ${ }^{1} \mathrm{H}-\mathrm{NMR}$ of the monomer TDA-V is shown in Figure 6. The signals at $\delta=9.57 \mathrm{ppm}$ is due to the $\mathrm{N}-\mathrm{H}$ protons, $\delta=7.26$ and 7.18 are due to the eight aromatic protons, $\delta=3.85 \mathrm{ppm}$ is accounted for four protons of the $-\mathrm{NH}_{2}$ group and the $\mathrm{CH}_{2}$ protons appear at $\delta=3.80 \mathrm{ppm}$. When compared to the ${ }^{1} \mathrm{H}$-NMR spectrum of 4,4'-diaminodiphenyl methane, the signal due to $\mathrm{N}-\mathrm{H}$ protons at $\delta=9.57 \mathrm{ppm}$ confirms the formation of thioamide group in the monomer TDA-V.

\subsection{Polymer Synthesis}

Scheme 1 Illustrates the route for synthesis of poly (azo- methine amide)s with thiourea groups PAM(I - VI) by the polycondensation of TCA with aromatic diamines TDA(I - VI) utilizing triphenylphosphite and pyridine as condensing agents in NMP. Polymerization reactions proceeded in a homogeneous manner and polymers did not phase out of the reaction medium. The inherent viscosity, yield of polymerizations and solubility of the polymers are summarized in Table 1.

Polyamides were obtained in good yield and the inherent viscosity values indicated the formation of medium to high molecular weight polymers [29]. Due to the ladder type structure which creates a cross-link effect makes these polyamides less soluble when compared to the polymers with either azomethine or thiourea groups reported earlier $[4,8]$. Chemical stability of these ladder type polyamides makes them suitable for the removal of metal ions from industrial wastes.

\subsection{Polymer Characterization}

The structure of poly(azometine amide)s (PAMs) were confirmed with FT-IR and ${ }^{1} \mathrm{H}$-NMR spectroscopes. IR spectra of representative polyamides are shown in Figure 7. When compared to the monomer TDA-IV (Figure 4) the $\mathrm{NH}_{2}$ signals appears as doublet at $3268 \mathrm{~cm}^{-1}$ is not present in the polymers and the -NH St. frequency of the amide link appears as a broad band in the range 3304 $3325 \mathrm{~cm}^{-1}$. Similarly, when compared to the tetracarboxylic acid monomer TCA (Figure 2) the $\mathrm{C}=\mathrm{O}$ stretching frequency of the acid group (appeared at $1687 \mathrm{~cm}^{-1}$ ) is not present in the polymers and the amide $\mathrm{C}=\mathrm{O}$ St. frequency appears in the range $1666-1668 \mathrm{~cm}^{-1}$ which 


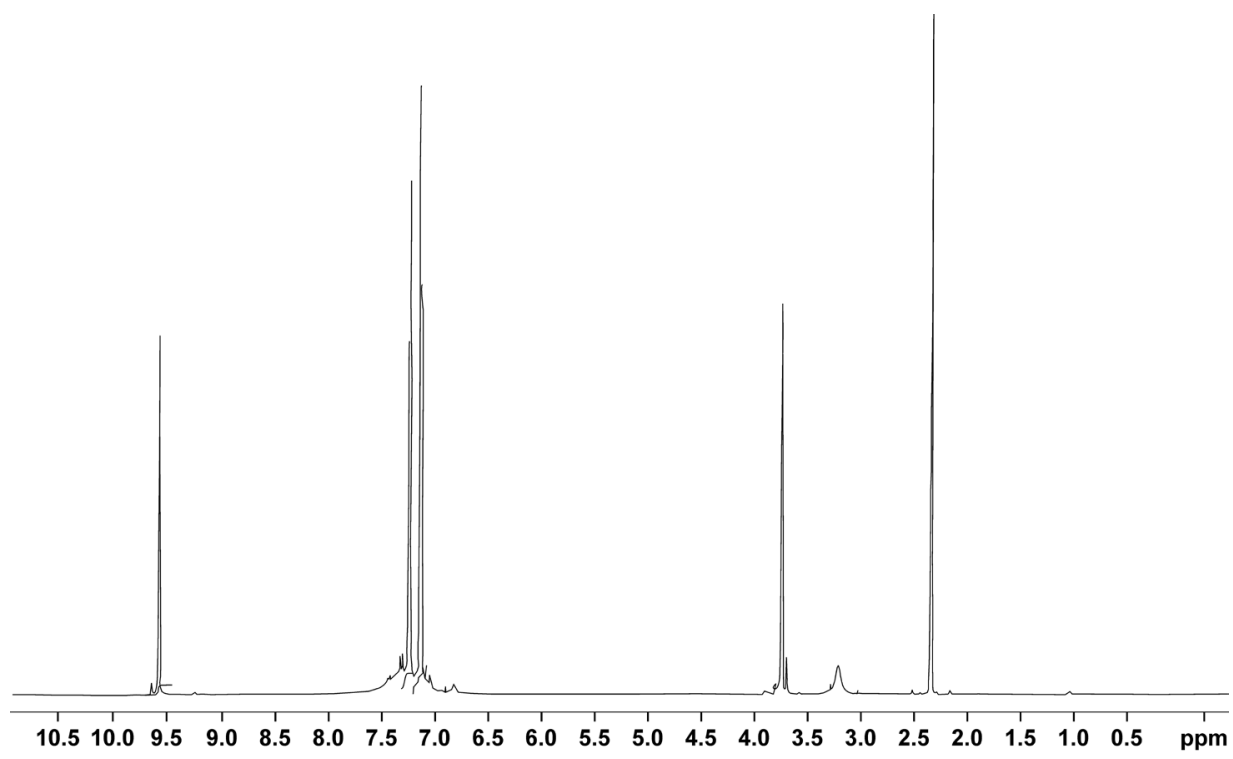

Figure 6. ${ }^{1} \mathrm{H}$-NMR-Spectrum of TDA-V.
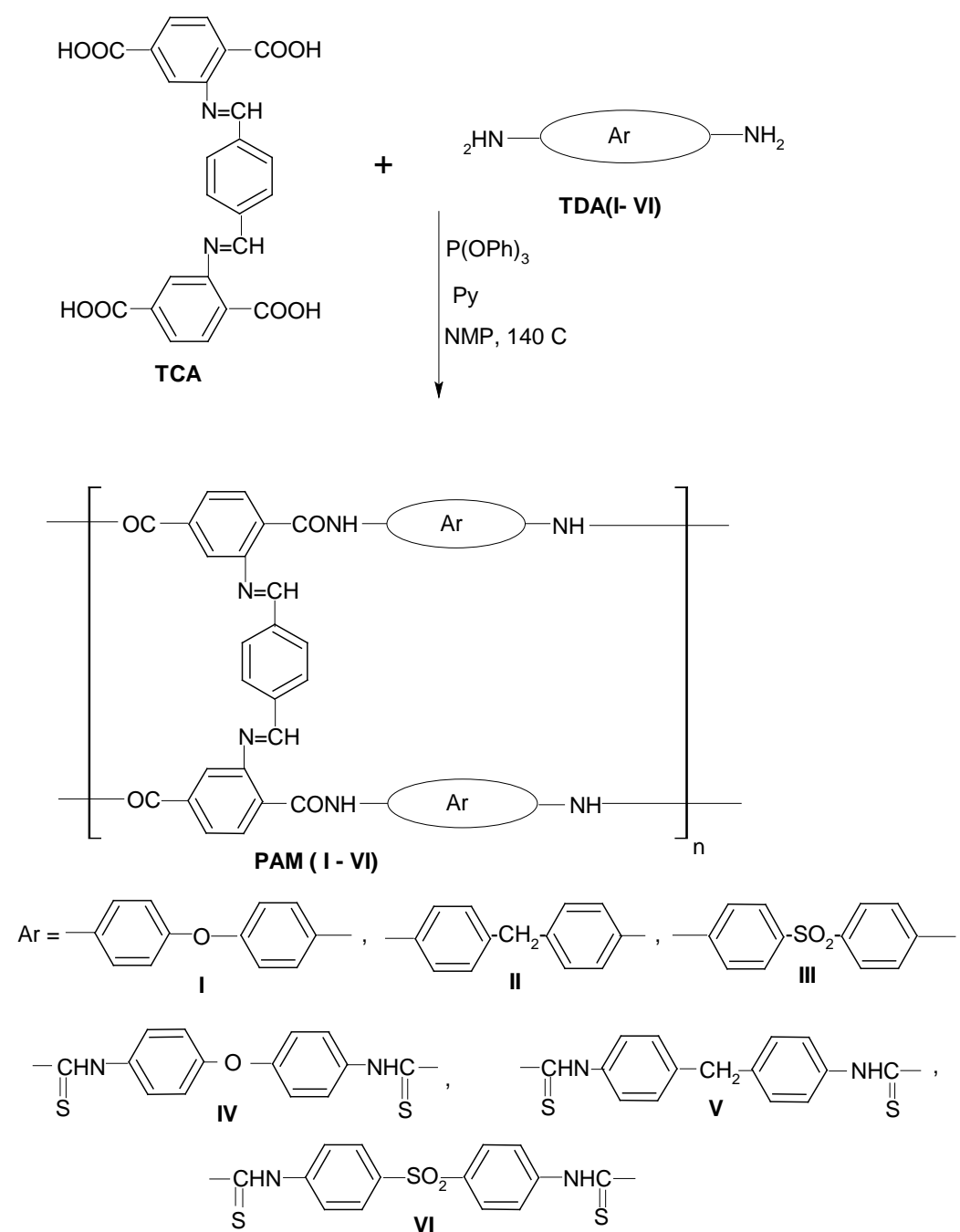

Scheme 1. Reaction scheme for synthesis of poly(azomethine amide)s. 
Table 1. Yield, inherent viscosity and solubility of the polymers.

\begin{tabular}{cccccccc}
\hline Polymer & Yield $\%$ & $\eta_{\text {inh }}{ }^{*}$ g/dL & DMF & NMP & DMSO $^{\#}$ & Pyridine & Benzene \\
\hline PAM-I & 93 & 0.46 & +- & +- & ++ & +- & - \\
PAM-II & 91 & 0.38 & +- & +- & ++ & +- & +- \\
PAM-III & 89 & 0.41 & ++ & +- & ++ & +- & +- \\
PAM-IV & 91 & 0.44 & +- & ++ & ++ & +- & +- \\
PAM-V & 86 & 0.39 & +- & ++ & ++ & +- & +- \\
PAM-VI & 81 & 0.43 & ++ & ++ & ++ & ++ & +- \\
\hline
\end{tabular}

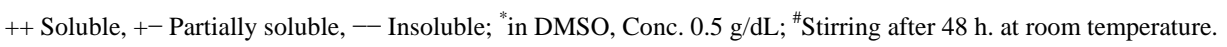

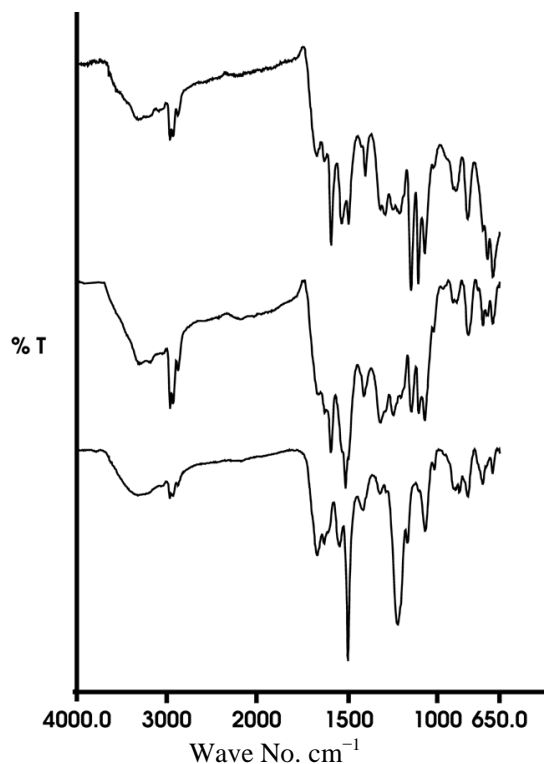

Figure 7. IR-Spectra of polymers PAM-II, PAM-IV and PAM-VI.

confirms the formation of amide links in the polymers. The amide II band appears in the range $1491-1508 \mathrm{~cm}^{-1}$ in all the polyamides. The imine - $\mathrm{CH}$ St. frequency appears at $2966 \mathrm{Cm}^{-1}$. ${ }^{1} \mathrm{H}-\mathrm{NMR}$ spectrum of PAM-VI is shown in Figure 8. Due to the complex nature of the aromatic acid and diamine parts, the signals obtained were broad. Broad and ill resolved peaks in ${ }^{1} \mathrm{H}-\mathrm{NMR}$ spectra are accounted for the formation of polyamides in which the polymer chains distort the shielding effect [30]. The N-H signals of the amide link appear at $\delta=10.9$ ppm. The $-\mathrm{N}=\mathrm{CH}$ - signal appear at $\delta=8.24 \mathrm{ppm}$ and the signals $\delta=8.0-6.13 \mathrm{ppm}$ are due to the complex aromatic protons of acid and diamines parts of the monomers. ${ }^{1} \mathrm{H}-\mathrm{NMR}$ spectrum of the polymer PAM-V is shown in Figure 9. The amide protons appear at $\delta=10.6$ ppm. $-\mathrm{N}=\mathrm{CH}$ - protons appear at $\delta=8.5 \mathrm{ppm}$ and the signals at $\delta=8.1-6.5 \mathrm{ppm}$ are due to the aromatic protons.

\subsection{Thermal Properties}

The thermal stability of the polyamides is summarized in
Table 2. The $10 \%$ and $20 \%$ weight loss temperatures for PAMs were measured by means of TGA analysis in nitrogen at a heating rate of $10^{\circ} \mathrm{C} \mathrm{min}^{-1}$ and were found to be in the range of $245^{\circ} \mathrm{C}-295^{\circ} \mathrm{C}$ and $315^{\circ} \mathrm{C}-475^{\circ} \mathrm{C}$ respectively. The amount of residue of poly(azomethine amide)s at $850^{\circ} \mathrm{C}$ in nitrogen was in the range $19 \%-47 \%$. Considering the initial weight loss of the polymers for the occluded moisture and solvent these polymers are thermally stable. Polymers with thiourea groups shows less stability when compared to the polyamides derived from simple diamines.

\section{Metal Ion Adsorption Studies}

\subsection{Effect of pH on Adsorption}

The experimental results for the $\mathrm{Cu}^{2+}$ and $\mathrm{Cd}^{2+}$ removal under increasing initial solution $\mathrm{pH}$ values by PAM-V and PAM-II respectively is shown in Figure 10. The initial metal ion concentrations of $\mathrm{Cu}^{2+}$ and $\mathrm{Cd}^{2+}$ are 300 $\mathrm{mg} / \mathrm{l}$ and $200 \mathrm{mg} / \mathrm{l}$ respectively. Contact time was kept at 1h. The loading capacities of the polymer increases with increasing $\mathrm{pH}$ and beyond a $\mathrm{pH}$ value of 6 it remains almost constant. $\mathrm{pH}$ is a critical parameter in adsorption because it influences the equilibrium by affecting the speciation of the heavy metal ions in solution, the concentration of competing hydrogen ions, and the chemistry of active binding sites on the adsorbent [31]. The results presented in Figure 10 shows that polyamides exhibited increasing affinity with decreasing acidity. At acidic $\mathrm{pH}$ values, protonation of the adsorbing sites (azomethine, amide, and thiourea) takes place in the polymer, thus reducing the binding ability with metal ions. On the other hand at $\mathrm{pH}>6$ the functional groups present in the adsorbent is deprotonated and their metal binding capacity increases. Hence an optimal pH value of 6 was fixed for further adsorption studies.

\subsection{Effect of Adsorption Time}

The adsorption solution of $\mathrm{Cu}^{2+}$ and $\mathrm{Cd}^{2+}$ sampled at different time ranging from $20-100 \mathrm{~min}$ at a $\mathrm{pH}$ of 6 to investigate the effect of contact time on the adsorption rate by PAM-VI and PAM-III respectively. Initial con- 


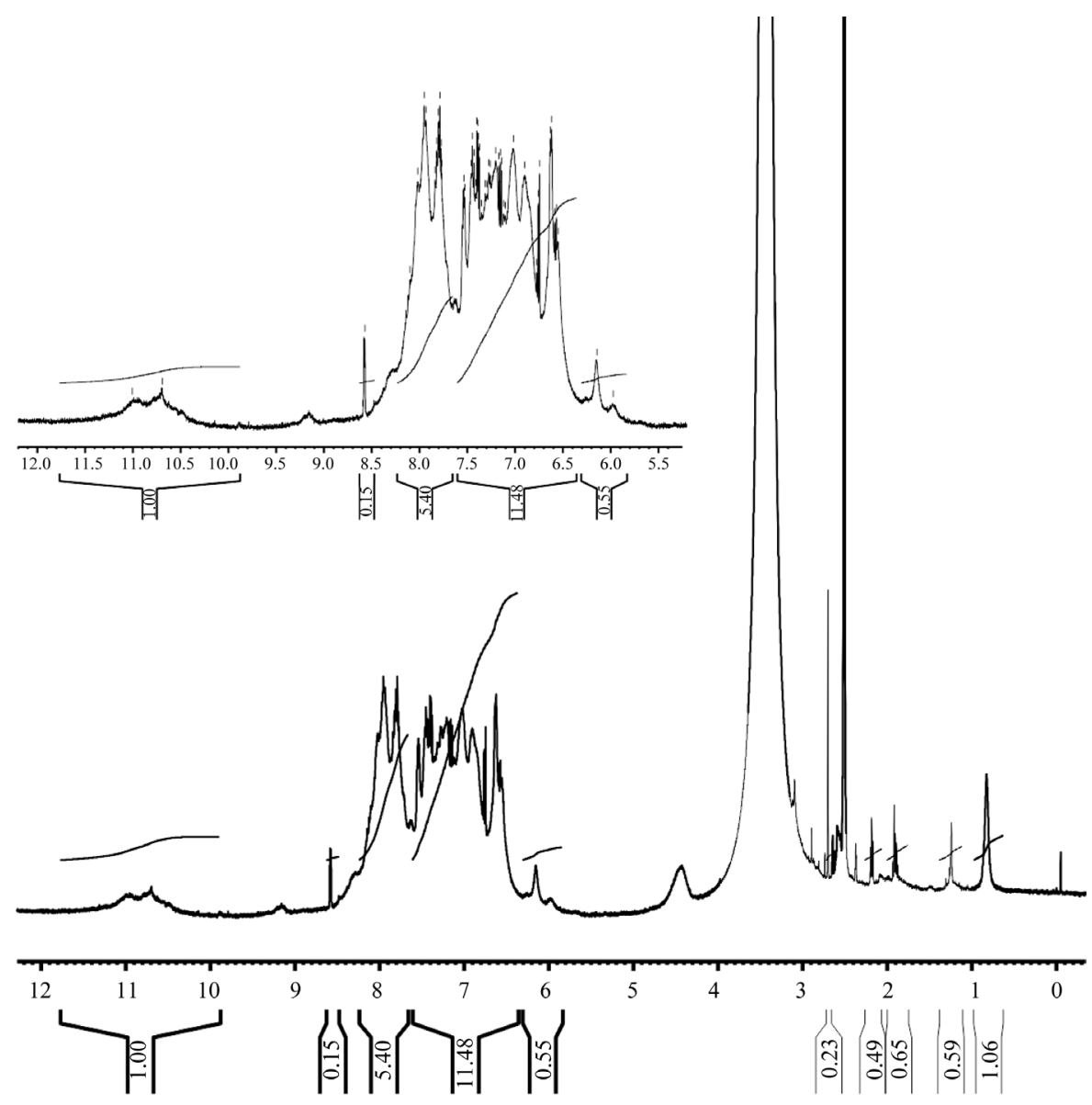

Figure 8. ${ }^{1}$ H-NMR-Spectrum of PAM-VI.

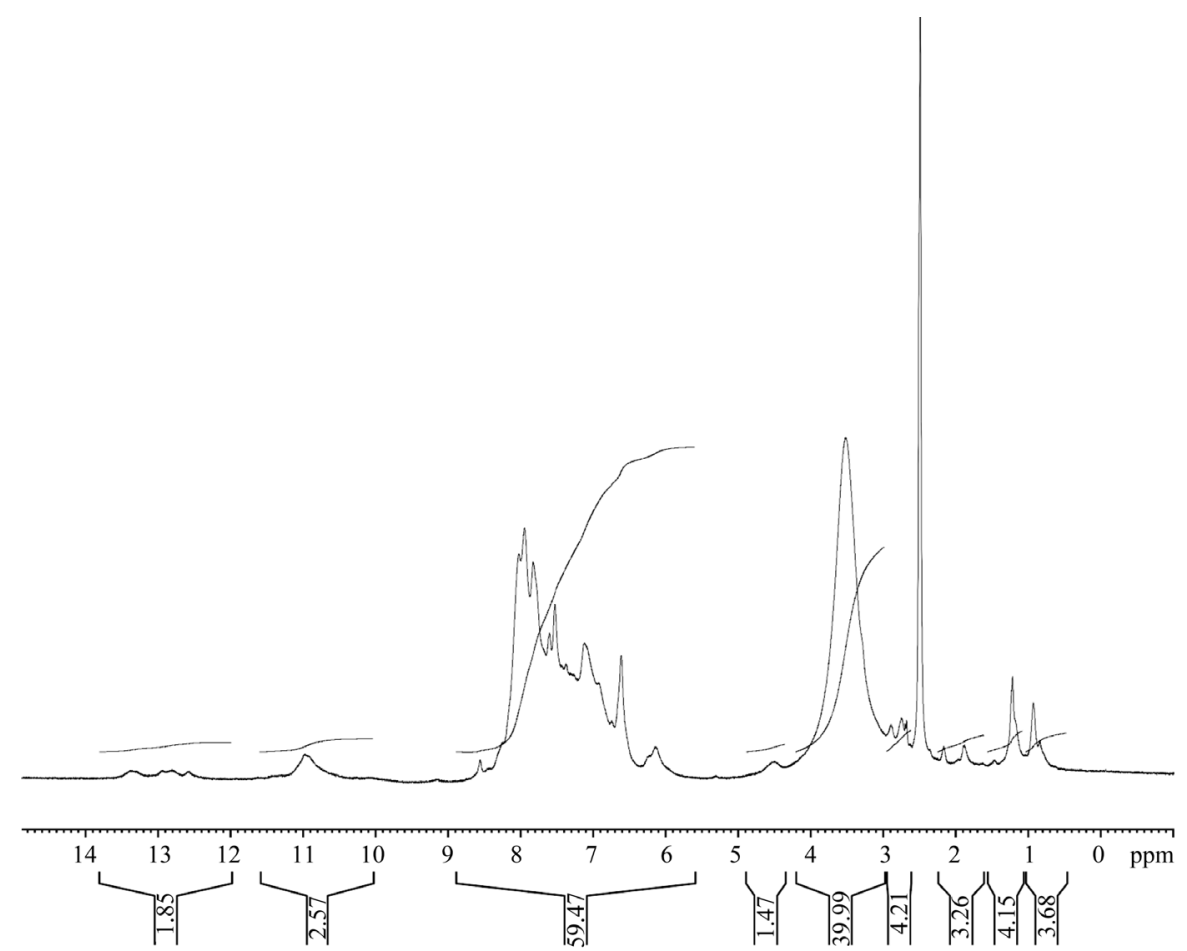

Figure 9. ${ }^{1}$ H-NMR-Spectrum of the polymer PAM-V. 
Table 2. Thermal properties of polymers.

\begin{tabular}{cccc}
\hline Polymer & $\mathrm{T}_{10}\left({ }^{\circ} \mathrm{C}\right)$ & $\mathrm{T}_{20}\left({ }^{\circ} \mathrm{C}\right)$ & $\begin{array}{c}\text { Char Yield }{ }^{\mathrm{a}}(\%) \\
\text { at } 850^{\circ} \mathrm{C}\end{array}$ \\
\hline PAM-I & 265 & 475 & 19 \\
PAM-II & 280 & 460 & 46 \\
PAM-III & 285 & 410 & 47 \\
PAM-IV & 295 & 387 & 38 \\
PAM-V & 265 & 315 & 14 \\
PAM-VI & 245 & 330 & 25 \\
\hline
\end{tabular}

$\mathrm{T}_{10}$ : $10 \%$ Weight loss temperature; $\mathrm{T}_{20}: 20 \%$ Weight loss temperature; ${ }^{\mathrm{a}} \mathrm{Re}-$ sidual weight in $\%$ at $850^{\circ} \mathrm{C}$.

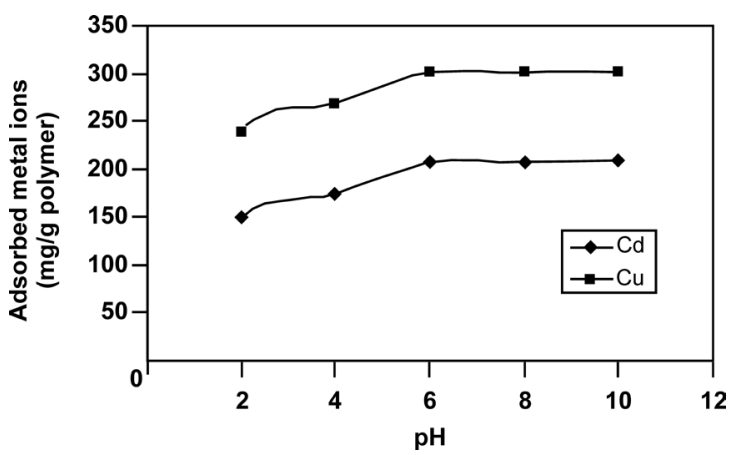

Figure 10. Effect of pH on adsorption.

centrations were kept at $300 \mathrm{mg} / \mathrm{l}$ and $200 \mathrm{mg} / \mathrm{l}$ of $\mathrm{Cu}^{2+}$ and $\mathrm{Cd}^{2+}$ respectively. The result was plotted in Figure 11. The adsorption equilibrium was established at $20 \mathrm{~min}$. A rapid adsorption was achieved during the initial stage itself, there by establishing the high efficiency of the polymers. More than $94 \%$ of $\mathrm{Cu}^{2+}$ and $\mathrm{Cd}^{2+}$ were adsorbed at 20 min contact time. This rapid adsorption phenomenon is advantageous in process applications. All further batch adsorption experiments were conducted for $1 \mathrm{~h}$. for attaining the maximum possible sorption.

\subsection{Effect of Initial Concentration of Metal Ions on Adsorption}

Adsorption isotherms describe how adsorption interacts with adsorbents and are important in optimizing the adsorbents. The experimental adsorption data of $\mathrm{Cu}^{2+}$ and $\mathrm{Cd}^{2+}$ on PAM-VI and PAM-III respectively is shown in Figure 12. The experiments were carried out at a pH of 6 and contact time of $1 \mathrm{~h}$. The adsorption capacity increases linearly with increase in the initial metal ions concentration up to the experimentally examined concentration of $500 \mathrm{ppm}$. for both $\mathrm{Cu}^{2+}$ and $\mathrm{Cd}^{2+}$ ions. The results suggests that the adsorption sites on the poly(azomethine thiourea amide)s are not saturated with $\mathrm{Cu}^{2+}$ and $\mathrm{Cd}^{2+}$ metal ions even at concentrations of $500 \mathrm{mg} / \mathrm{l}$. This is probably due to the increased number of adsorption sites such as $-\mathrm{N}=\mathrm{CH}$-, -CONH- and -NHCS- in the polymer repeat unit. A detailed kinetic investigation is under pro-

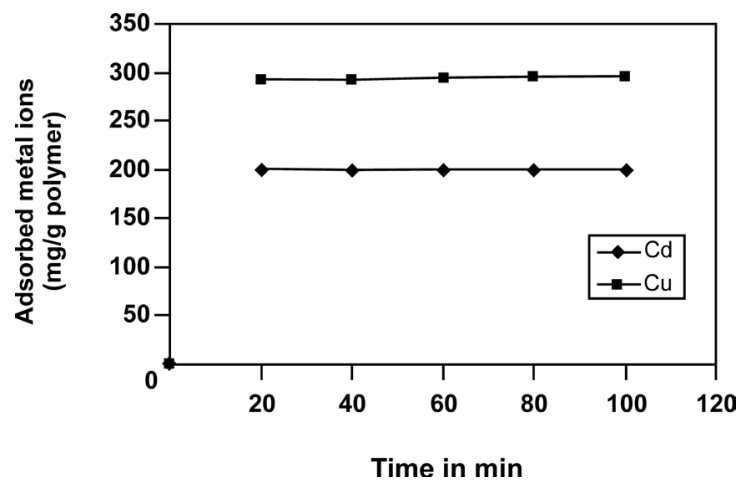

Figure 11. Effect of contact time on adsorption.

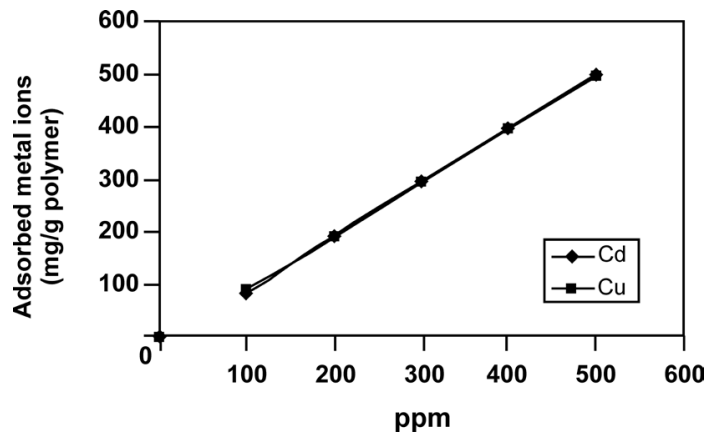

Figure 12. Effect of initial metal ion concentration on adsorption.

gress and the results will appear shortly.

\subsection{Selectivity and Repeated Use}

The selectivity of PAM-I and PAM-IV for different metals [Pb (II), Cu (II), Cr (IV) and Cd (II)] was investigated and the results are presented in Table 3.

$\mathrm{K}_{2} \mathrm{Cr}_{2} \mathrm{O}_{7}, \mathrm{CdSO}_{4} \cdot 8 \mathrm{H}_{2} \mathrm{O}, \mathrm{CuSO}_{4} \cdot 5 \mathrm{H}_{2} \mathrm{O}$ and $\mathrm{Pb}(\mathrm{NO})_{3}$ solutions of initial concentration of $300 \mathrm{mg} / \mathrm{L}$ each were mixed and the final solution was adjusted to a $\mathrm{pH}$ of 6 with contact time of $1 \mathrm{~h}$. Results show the selectivy order is $\mathrm{Pb}$ (II) $>\mathrm{Cu}$ (II) $>\mathrm{Cr}$ (IV) $>\mathrm{Cd}$ (II). The results also show that polyamides containing thiourea groups (PAMIV) and without thiourea groups (PAM-I) are equally effective in selective removal. The adsorbent efficiency for multiple adsorption/desorption was tested for four cycles using $2 \mathrm{M} \mathrm{HCl}$ and the results indicate that the polymers are highly efficient even after four cycles.

\subsection{IR and Surface Morphology Analysis of Metal Adsorbed Polymers}

FT-IR spectra of $\mathrm{Cu}^{2+}$ adsorbed PAM-V and $\mathrm{Cd}^{2+}$ adsorbed PAM-II are shown in Figure 13. When compared to the IR spectra of PAM-V and PAM-II the appreciable changes in the frequencies of the metal ion adsorbed PAMs are: 1$)$ the imine - $\mathrm{CH}$ stretching frequency of the polymers $\left(2966 \mathrm{Cm}^{-1}\right)$ completely disap- 
Table 3. Selectivity and repeated use of polyamides.

\begin{tabular}{|c|c|c|c|c|}
\hline \multirow{2}{*}{ Cycle No } & \multicolumn{4}{|c|}{ Adsorption (mg/g) Polymer: PAM-I } \\
\hline & $\mathrm{Pb}(\mathrm{II})$ & $\mathrm{Cu}(\mathrm{II})$ & $\mathrm{Cr}(\mathrm{IV})$ & Cd (II) \\
\hline 1 & 109.6 & 103.6 & 72.6 & 64.3 \\
\hline 2 & 108.5 & 103.2 & 69.3 & 69.3 \\
\hline 3 & 105.3 & 102.4 & 68.1 & 68.1 \\
\hline 4 & 100.4 & 99.2 & 67.6 & 67.6 \\
\hline \multicolumn{5}{|c|}{ Adsorption (mg/g) Polymer: PAM-IV } \\
\hline 1 & 108.9 & 105.2 & 80.1 & 59.4 \\
\hline 2 & 106.7 & 102.6 & 72.8 & 48.4 \\
\hline 3 & 104.2 & 99.4 & 68.2 & 46.2 \\
\hline 4 & 100.5 & 96.7 & 67.3 & 44.3 \\
\hline
\end{tabular}

Initial concentration: $\mathrm{Pb}(\mathrm{II})=300 \mathrm{mg} / \mathrm{l}, \mathrm{Cu}(\mathrm{II})=300 \mathrm{mg} / \mathrm{l}, \mathrm{Cr}(\mathrm{IV})=300 \mathrm{mg} / \mathrm{l}$ and Cd (II) = $300 \mathrm{mg} / \mathrm{l} . \mathrm{pH}=6.0 . \mathrm{Contact}$ time = 1 h.

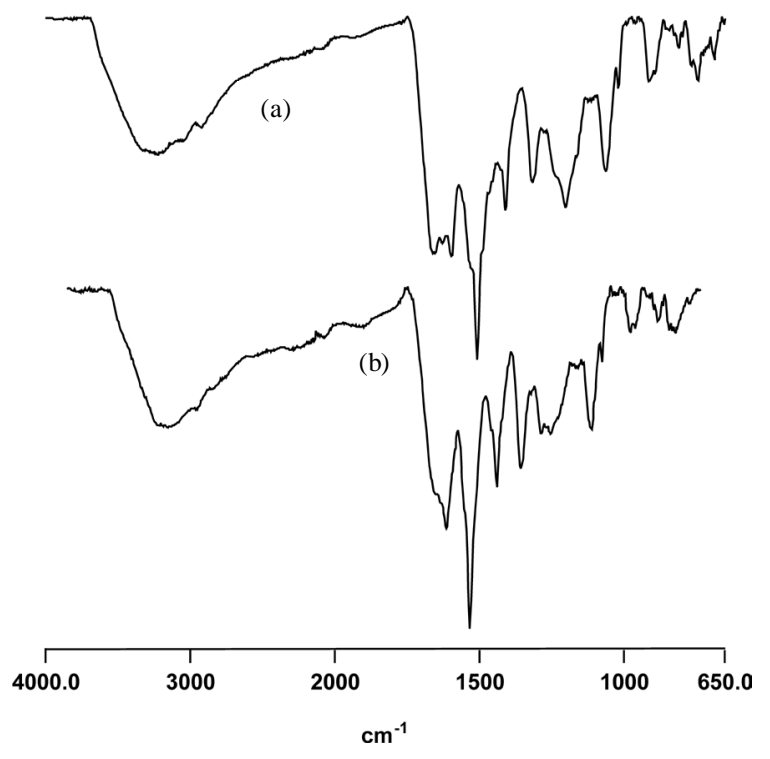

Figure 13. FT-IR spectra of (a) $\mathrm{Cu}^{2+}$ adsorbed PAM-V and (b) $\mathrm{Cd}^{2+}$ adsorbed PAM-II.

pears in the metal adsorbed polymers; 2) the shape of the amide $\mathrm{C}=\mathrm{O}$ St. frequency and $-\mathrm{N}=\mathrm{CH}-\mathrm{St}$. frequency undergone significant changes and shifts to a higher frequency; 3) broadening and shifting in the -NH St. frequency of the amide links in the metal ion adsorbed polymer; 4) the change in the shape of $C=S$ St. frequencies of the thioamide groups. The shifting and change of shape of the binding sites in the metal ion adsorbed polymer frequencies suggest the possible binding between the amide, azomethine and thioamide groups of the polymer with the metal ions during adsorptions.

The surface morphology of raw polymers and metal adsorbed polymers are shown in Figure 14.

As is clearly seen here (Figures 14(a) and (b)) the polymers have a rough and porous surface. Layers of metal adsorbed on the polymer surfaces are seen Figures 14(c) and (d).

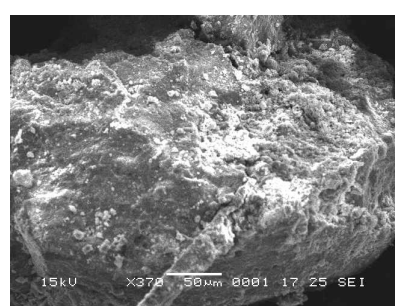

(a)

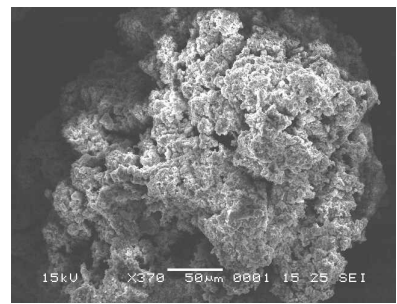

(c)

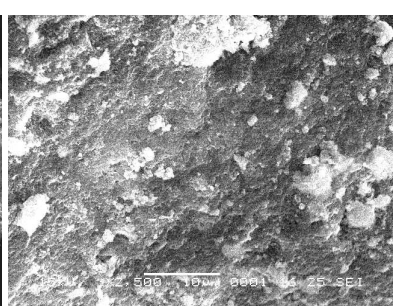

(b)

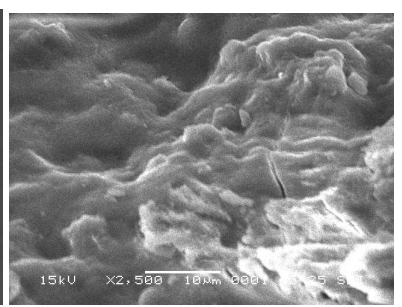

(d)
Figure 14. SEM micrographs of polyamides and metal adsorbed polyamides. (a) PAM-I; (b) PAM-IV; (c) $\mathrm{Cu}^{2+} \mathrm{Ad}-$ sorbed PAM-I; (d) Cd Cd $^{2+}$ Adsorbed PAM-IV.

\section{Conclusion}

Ladder type poly(azomethine amide)s bearing phenythiourea units were successfully synthesized from new azomethine tetracarboxylic acid monomer with good thermal stability. The polyamides were chemically resistant and are potential candidates for the removal of heavy metal ions from industrial wastes. The loading capacity of polymers towards $\mathrm{Cu}^{2+}$ and $\mathrm{Cd}^{2+}$ are very high to the extent of $495 \mathrm{mg} / \mathrm{g}$ of polymer. Competitive adsorption and reuse of the polymers towards $\mathrm{Pb}$ (II), $\mathrm{Cu}(\mathrm{II}), \mathrm{Cr}(\mathrm{IV})$ and Cd(II) metal ions reflect their high efficiency.

\section{Acknowledgements}

Partial financial support in the form of PG Grant Chemistry by UGC India is acknowledged. 


\section{REFERENCES}

[1] P. E. Cassidy, "Thermally Stable Polymers, Synthesis and Properties,” Marcel Dekker, New York, 1980.

[2] A. Iwan and D. Sek, "Processable Polyazomethines and Polyketanils: From Aerospace to Light-Emitting Diodes and Other Advanced Applications," Progress in Polymer Science, Vol. 33, No. 3, 2008, pp. 289-345. http://dx.doi.org/10.1016/j.progpolymsci.2007.09.005

[3] M. Grigoras, O. Cataneseu and C. L. Simionesen, "Poly (azomethine)s," Revue Roumaine de Chimie, Vol. 46, No. 9, 2001, pp. 927-939.

[4] M. Grigoras, C. Otilia and O. Catanescu, "Imino Oligomers and Polymers," Journal of Macromolecular Science: Part C, Vol. 44, No. 2, 2004, pp. 131-173.

[5] B. Suseela, B. Bhaskar and P. Subhash, "Synthesis and Characterization of New Polyimides and Polyamide-Imides Containing Azomethine Groups in the Polymer Backbone,” Polymer Bulletin, Vol. 22, No. 4, 1989, pp. 371378.

[6] J. A. Mikroyannidias, "Aromatic Polyisophthalamides with $N$-Benzylidine Pendant Groups,” Journal of Polymer Science Part A: Polymer Chemistry, Vol. 30, No. 11, 1992, pp. 2371-2377.

[7] L. Ravikumar, R. Saravanan, K. Saravanamani and M. Karunagaran, "Synthesis and Characterization of New Polyamides with Substitutions in the Pendent Benzylidine Rings,” Designed Monomers and Polymers, Vol. 12, No. 4, 2009, pp. 291-303. http://dx.doi.org/10.1163/156855509X448262

[8] K. Yamamoto, M. Higuchi and H. Kanazawa, "Novel Linear Hyperbranched Aromatic Polyamide with Phenylazomethine Units for Chemical Recycling," Chemistry Letters, Vol. 31, No. 7, 2002, pp. 692-693. http://dx.doi.org/10.1246/cl.2002.692

[9] B. J. Vasanthi, L. Ravikumar and A. Selvaraj, "Corrision Control of Phenylthiourea Polymers on Aluminium in Alkaline Medium,” Materials and Corrosion, Vol. 59, No. 1, 2008, pp. 14-20. http://dx.doi.org/10.1002/maco.200704076

[10] M. Sivadhayanithy, L. Ravikumar and C. Rengaswamy, "Desin and Synthesis of New Thermally Stable Polyesters Containing Azo and Phenylthiourea Units,” High Performance Polymers, Vol. 19, No. 1, 2007, pp. 62-75. http://dx.doi.org/10.1177/0954008306069394

[11] B. J. Vasanthi and L. Ravikumar, "Synthesis and Characterization of New Poly(Azomethine Ester)s Having Phenylthiourea Units,” European Polymer Journal, Vol. 43, No. 10, 2007, pp. 4325-4331. http://dx.doi.org/10.1016/j.eurpolymj.2007.07.037

[12] I. Delfanne and G. Levesque, "Polythioamides and Poly (1,3,4-thiadiazole) Synthesis from Dimethyl Tetrathioterephthalate," Macromolecules, Vol. 22, No. 6, 1989, pp. 2589-2592. http://dx.doi.org/10.1021/ma00196a007

[13] L. Ravikumar, V. Sengodan, M. Balajiprasad, K. Gopalakrishnan and K. Sethupathi, "Synthesis and Characterization of Conductive Blends of Polyaniline with Poly (Azomethine Ester)s,” International Journal of Polymeric Materials and Polymeric Biomaterials, Vol. 56, No. 2,
2007, pp. 197-206.

http://dx.doi.org/10.1080/00914030600773628

[14] M. Sivadhayanithy, L. Ravikumar and T. Ramachandran, "Synthesis and Characterization of Thermally Stable Novel Polymers Containing Phenylthiourea, Azo and Sulfone Groups in the Backbone," Journal of the Chilean Chemical Society, Vol. 52, No. 3, 2007, pp. 1230-1234. http://dx.doi.org/10.4067/S0717-97072007000300007

[15] A. Kausar, S. Zulfiqar, Z. Ahmad and M. I. Sarwar, "Novel Processable and Heat Resistance Poly(Phenylthiourea Azomethine Imide)s: Synthesis and Characterization," Polymer Degradation and Stability, Vol. 95, No. 9, 2010, pp. 1826-1833.

http://dx.doi.org/10.1016/j.polymdegradstab.2010.05.002

[16] N. Kabay, M. Demiccioglu, H. Elcinci, M. Yuksel, M. Saglam, M. Akcay and M. Streat, "Removal of Metal Pollutants Cd(II) and Cr(III) from Phosphoric Acid Solutions by Chelating Resins Containing Phosphoric or Diphosphoric Groups,” Industrial \& Engineering Chemistry Research, Vol. 37, No. 6, 1998, pp. 2541-2547. http://dx.doi.org/10.1021/ie9704881

[17] S. Y. Chen, W. Shen, F. Yu and H. P. Wang, "Kinetic and Thermodynamic Studies of Adsorption of $\mathrm{Cu}^{2+}$ and $\mathrm{Pb}^{2+}$ onto Amidoximated Bacterial Cellulose,” Polymer Bulletin, Vol. 63, No. 2, 2009, pp. 283-297. http://dx.doi.org/10.1007/s00289-009-0088-1

[18] H. L. Vasconcelous, V. T. Favere, N. S. Gonealves and M. C. M. Laranjeira, "Chitoson Modified with Reactive Blue 2 Dye on Adsorption Equilibrium of $\mathrm{Cu}(\mathrm{II})$ and $\mathrm{Ni}(\mathrm{II})$ Ions," Reactive and Functional Polymers, Vol. 67, No. 10, 2007, pp. 1052-1060. http://dx.doi.org/10.1016/j.reactfunctpolym.2007.06.009

[19] S. S. Gupta and K. G. Bhattacharyya, "Removal of Cd(II) from Aquous Solutions by Kaolinite Montmorillonite and Their Poly(Oxo Zirconium) and Tetrabutylammonium Derivatives,” Journal of Hazardous Materials, Vol. 128, No. 2-3, 2006, pp. 247-257. http://dx.doi.org/10.1016/j.jhazmat.2005.08.008

[20] G. Zuo and M. Muhammed, "Thiourea-Based Coordinating Polymers: Synthesis and Binding to Noble Metals," Reactive Polymers, Vol. 24, No. 3, 1995, pp. 165-181. http://dx.doi.org/10.1016/0923-1137(94)00082-G

[21] A. Lezzi and S. Cbianco, "Chelating Resins Supporting Dithiocarbamate and Methyl Thiourea Groups in Adsorption of Heavy Metal Ions," Journal of Applied Polymer Science, Vol. 54, No. 7, 1994, pp. 889-897.

[22] M. Monier, D. M. Ayad and A. A. Sarhan, “Adsorption of $\mathrm{Cu}(\mathrm{II}), \mathrm{Co}(\mathrm{II})$ and $\mathrm{Ni}(\mathrm{II})$ Ions by Modified Magnetic Chitosan Chelating Resin,” Journal of Hazardous Materials, Vol. 177, No. 1-3, 2010, pp. 962-970. http://dx.doi.org/10.1016/j.jhazmat.2010.01.012

[23] R. A. Ravikumar and R. K. Hussian, "Synthesis of Functionalized Phenolformaldehyde Polymer Resins by the Reaction of 2,4-Dihydroxyacetophenone Formaldehyde Resins with Various Amines and Their Metal Uptake Properties,” Journal of Applied Polymer Science, Vol. 92, No. 3, 2004, pp. 1501-1509. http://dx.doi.org/10.1002/app.20076

[24] A. M. Donia, A. A. Atia and A. M. Henish, "Efficient 
Removal of Hg(II) Using Magnetic Chelating Resin Derived from Copolymerization of Bisthiourea/Thiourea/ Glutaraldehyde," Separation and Purification Technology, Vol. 60, No. 1, 2008, pp. 46-53.

http://dx.doi.org/10.1016/j.seppur.2007.07.045

[25] L. Ravikumar, S. S. Kalaivani, A. Murugesan, T. Vidhyadevi, G. Karthik, S. D. Kirupha and S. Sivanesan, "Synthesis, Characterization, and Heavy Metal Ion Adsorption Studies of Polyamides, Polythioamides Having Pendent Chlorobenzylidine Rings,” Journal of Applied Polymer Science, Vol. 122, No. 3, 2011, pp. 1634-1642. http://dx.doi.org/10.1002/app.33968

[26] A. Murugesan, L. Ravikumar, V. SathyaSelvaBala, V. SenthilKumar, T. Vidhyadevi, S. D. Kirupha, S. S. Kalaivani, S. Krithiga and S. Sivanesan, "Removal of $\mathrm{Pb}(\mathrm{II})$, $\mathrm{Cu}(\mathrm{II})$ and $\mathrm{Cd}(\mathrm{II})$ Ions from Aqueous Solution Using Polyazomethineamides: Equilibrium and Kinetic Approach,” Desalination, Vol. 271, No. 1-3, 2011, pp. 199-208. http://dx.doi.org/10.1016/j.desal.2010.12.029

[27] A. Murugesan, T. Vidhyadevi, S. S. Kalaivani, M. P. Premkumar, L. Ravikumar and S. Sivanesan, "Kinetic and Thermodynamic Studies on the Removal of $\mathrm{Zn}^{2+}$ and $\mathrm{Ni}^{2+}$ from Their Aqueous Solution Using Poly(Phenylthiourea)Imine,” Chemical Engineering Journal, Vol. 197, 2012, pp. 368-378. http://dx.doi.org/10.1016/j.cej.2012.05.027

[28] S. D. Kirupha, A. Murugesan, T. Vidhyadevi, P. Baskaralingam, S. Sivanesan and L. Ravikumar, "Novel Polymeric Adsorbents Bearing Amide, Pyridyl, Azomethine and Thiourea Binding Sites for the Removal of $\mathrm{Cu}(\mathrm{II})$ and $\mathrm{Pb}$ (II) Ions from Aqueous Solution," Separation Science and Technology, Vol. 48, No. 2, 2013, pp. 254-262.

[29] J. Tan, C. Wang, W. Peng, G. Li and J. M. Jiang, "Synthesis, Characterization, and Properties of Novel Aromatic Polyamides Containing Phthalazinone Moiety," Polymer Bulletin, Vol. 62, No. 2, 2009, pp. 195-207. http://dx.doi.org/10.1007/s00289-008-0013-z

[30] A. K. Mohanty, D. Das, A. K. Panigrahi and M. Mishra, "Synthesis and Characterization of a Novel Polyamide: Polycondensation of 2,5-Diaminothiazole with Terephthalic Acid,” European Polymer Journal, Vol. 34, No. 12, 1998, pp. 1889-1898. http://dx.doi.org/10.1016/S0014-3057(98)00030-5

[31] A. Denizil, N. Sanli, B. Gavipean, S. Patir and G. Alsanck, "Methacryloylamidoglutamic Acid Incorporated Poros Poly(Methyl Methacrylate) Beads for Heavy-Metal Removal," Industrial \& Engineering Chemistry Research, Vol. 43, No. 19, 2004, pp. 6095-6010. http://dx.doi.org/10.1021/ie030204z 